\title{
Microstructure of Cool-drawing Austenitic Stainless Steel Wires Used for Metal Rubber
}

\author{
YANG Jian-chun ${ }^{1}$, DONG Xiu-ping ${ }^{2}$, MA Wan-li ${ }^{1}$, CHEN Shuai ${ }^{1}$ \\ Department of guns engineering, Ordnance engineering college, Shijiazhuang 050003, China \\ College of materials and mechanical engineering, Beijing technology and business university, Beijing \\ 100048,China)
}

\begin{abstract}
Keywords: cool-drawing; austenitic stainless steel wires; strain induced martensite; shuttle-shaped micro holes
\end{abstract}

\begin{abstract}
By the OM, SEM, TEM, and EBSD, the microstructures of cool-drawing austenitic stainless steel wires used for metal rubber were studied. The results showed that the microstructures of this steel wires were made up of $\alpha$ martensite phase, presenting twin and dislocation substructures, and residual austenite phase which was refined into micron dimension. The results also presented that there were so many Shuttle-shaped micro holes in this steel wires, lugging along drawing axis and cored by the hard particles second-phase. The further investigation indicates that the Cr17-Ni7 cool-drawing austenitic stainless steel wires were more applicable to use for the high-damp metal rubber.

All kinds of metal rubber elements have a spatial mesh structure, similar with the rubber polymer structure, which is crossed and hooked together by a metal wire. The structure has rubber elasticity while maintaining the metal excellent properties. It has a very broad application prospects of the metal rubber to be used in aerospace, defense, machinery, transportation and to made into the member in special conditions of damping, shock protection, filtration, sealing and heat conduction $^{[1]}$.

Now 18-8 austenitic stainless steel is the most used in the metal wire rubber member. Its microstructure has a significant impact for components performance. 18-8 series austenitic stainless steel is a very mature grades and is understood deep ${ }^{[2-4]}$. At the same time it is also reported in the literature for deformation induced martensite transformation caused by large deformation of this type of austenitic stainless steel in the rolling process ${ }^{[5-9]}$. However, metal rubber elements with $\Phi 0.1 \sim 0.5 \mathrm{~mm}$ is drew by stainless steel wire system ${ }^{[10]}$. Organizational changes triggered by drawing, especially the organization study of a scanning electron microscopy is still rare. Therefore, further study of the microstructure of cold-drawn state $0 \mathrm{Cr} 18 \mathrm{Ni}$ Ti stainless steel wire is necessary. In addition, the work in this paper made instructive recommendations for the choice of metal rubber components using in stainless steel wire materials.
\end{abstract}

\section{Experimental materials and methods}

The diameter metal rubber stainless steel wire generally take $\Phi 0.1 \sim 0.5 \mathrm{~mm}$, and it has confirmed that the species of Martensitic transformation of stainless steel wire are closely related to cold deformation. For convenience considerations of TEM experimental sample preparation, the 0Cr18Ni9Ti stainless steel wire of diameter $\Phi 14 \mathrm{~mm}$ and the finished with diameter $\Phi 6 \mathrm{~mm}$ by cold drawing as the research object, the rate of reduction of the is 83.67 percent and elongation of drawing for the last time is about $35 \%$, which has reached the stage of deformation fully induced transformation. The optical microscopy, scanning electron microscopy and transmission electron microscopy, EBSD observation experiment are taken for vertical and horizontal cross-section. A comprehensive analysis is taken of mechanism of strain-induced martensitic transformation and the sub-structure of martensite while 0Cr18Ni9Ti steel cold drawing. 


\section{Experimental results and analysis}

\subsection{The microstructure change of cold drawing stainless steel wire}

Figure 1 shows the optical microstructure of the longitudinal section and cross section of drawing 0Cr18Ni9Ti stainless steel wire. (a) and (b) figure is the cross-section of microscopic morphology. Grain is fine and uniform, and the grain boundary is not clear. The plate martensite can be observed when enlarged to about 500 times. (c) and (d) figure is the longitudinal section of microscopic morphology. It is observed that the organization is elongated a fiber along drawing direction and the boundaries is not easy to be identified. This is not only because its appearance changed when the wire was drawing strain, but also the inside grain became tensile deformation. The grain boundary became destruction and phase transformation occurred.
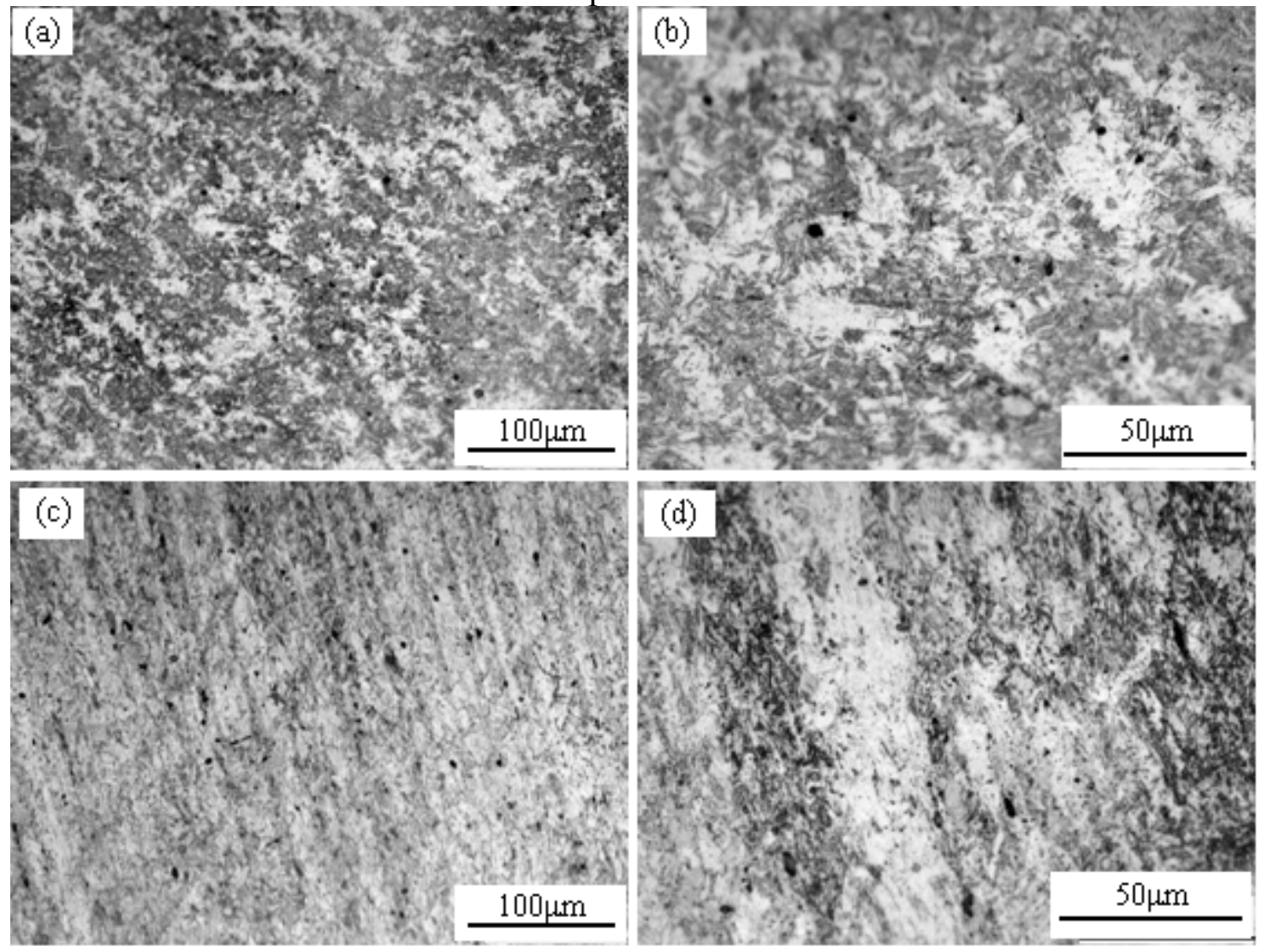

Fig. 1 Microstructures on sections of cool-drawing 0Cr18Ni9Ti wires
(a) (b) longitudinal section
(c) (d) cross section

\subsection{SEM analysis of cold-drawing steel wire}

Figure 2 is SEM micrographs and energy spectroscopy of cool-drawing austenitic stainless steel wires.(c) chart showed that some pits like circular is on the longitudinal section. (a) chart showed that pits are severely stretched in cross-section. The black particles inside is inferred to be Fe-Ni-Cr-Ti intermetallic compound as (b)(d) chart.

$0 \mathrm{Cr} 18 \mathrm{Ni9Ti}$ is a metastable supersaturated solid solution. M23C6 and MC is major carbides types of stainless steel.They have a limit of solubility curve in $\gamma$ phase. There is close relationship between grain boundary precipitation and intergranular corrosion. The hard and brittle intermetallic phases may also be formed in austenitic stainless steels. Such as $\sigma$ phase, its nominal composition is $\mathrm{FeCr}$, but the actual composition of the phase is $(\mathrm{FeNi})_{\mathrm{x}}(\mathrm{CrTi})_{\mathrm{y}} \cdot \sigma$ phase firstly appeared in the intersection of three grains and secondly the grain boundaries. When large deformation it will be formed on the twin boundary and grain interior debris. The main internal factors of $\sigma$ precipitation of austenite stainless steel are alloy composition and $\mathrm{Ti}$ is a strong element to produce $\sigma$ phase formation. It was significant to promote the formation of $\sigma$ phase when the chromium content reached 25\%. Therefore, under normal conditions in the 18-8 line of such relatively low-alloyed austenitic steels will not appear hard and brittle $\sigma$ phase. Because the cold deformation refined grain, 
increased nucleation position $\sigma$ phase, which contributed to the $\sigma$ phase precipitates in the grain boundaries and intragranular. It can be preliminary determined according to its chemical composition; in Figure 2 the black particles are likely to be $\sigma$ phase.
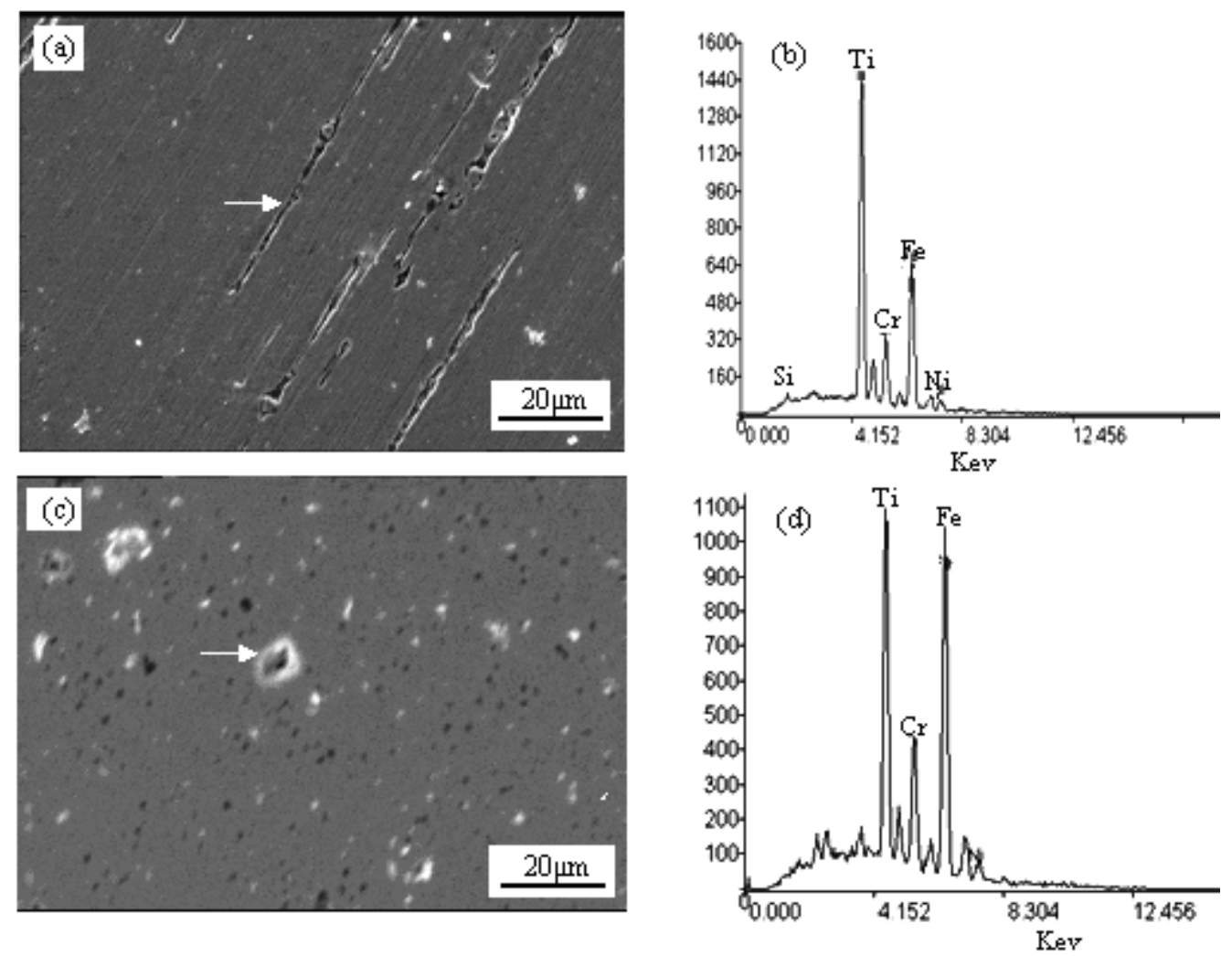

Fig. 2 SEM micrographs and energy spectroscopy of cool-drawing austenitic stainless steel wires

(a) longitudinal section (c) cross section

(b) (d) energy spectroscopy of black particles in micro holes

After martensitic transformation induced by the occurrence of strain, strengthening alloying element in the martensite forms supersaturated solid solution. It will have the strengthening organization pervaded the second phase on the martensitic matrix. These hard and brittle phases still are scattered throughout. Because it is relatively hard than matrix, it can not come compatible deformation with the matrix. Thus both ends along the direction of drawing and the matrix break away and micro holes is formed

Generally, the hard and brittle phase after solution treatment will be dissolved into the matrix, to some extent, which can prevent or control the adverse effects. Therefore, in the drawing process with reasonable intermediate heat treatment may improve the micro-holes generation. In addition, appropriate adjustments for the alloy composition of austenitic steels, removing Ti element which is strongly promoting $\sigma$ phase and reducing $\mathrm{Cr}$ Ni content, can inhibit the formation of $\sigma$ phase to some extent and furthermore control the number of micro holes.

\subsection{TEM micrographs of cool-drawing austenitic stainless steel wires}

Through the TEM experiments, we observed the detailed sub-structure of martensite, and found not only twin-substructured martensite (Figure 3 (a) micrographs of twin-substructured martensite, Figure 3 (b) diffraction patterns of twin-substructured martensite), but also dislocation-substructured martensite (As shown in Figure 3 (c)). Crushing morphology was found in the local position which is in longitudinal section of the sample found (As shown in Figure 3 (d) ), The diffraction pattern is annular spot .(As shown in Figure $3(\mathrm{e})$ ), the square ratio of its radius $\mathrm{R} 1^{2}$ $/ \mathrm{R} 2^{2} / \mathrm{R} 3^{2} / \mathrm{R} 4^{2} / \mathrm{R}^{2} / \mathrm{R} 6^{2}$ is equal to about 3: 4: 8:11: 12:16, if the calibration is $\gamma$ phase, it is determined that the morphology is the austenite. Here we analyze the formation of twin-substructured martensite and dislocation-substructured martensite in detail, as for the crushing morphology appeared in the local position will be discussed later EBSD experiments 

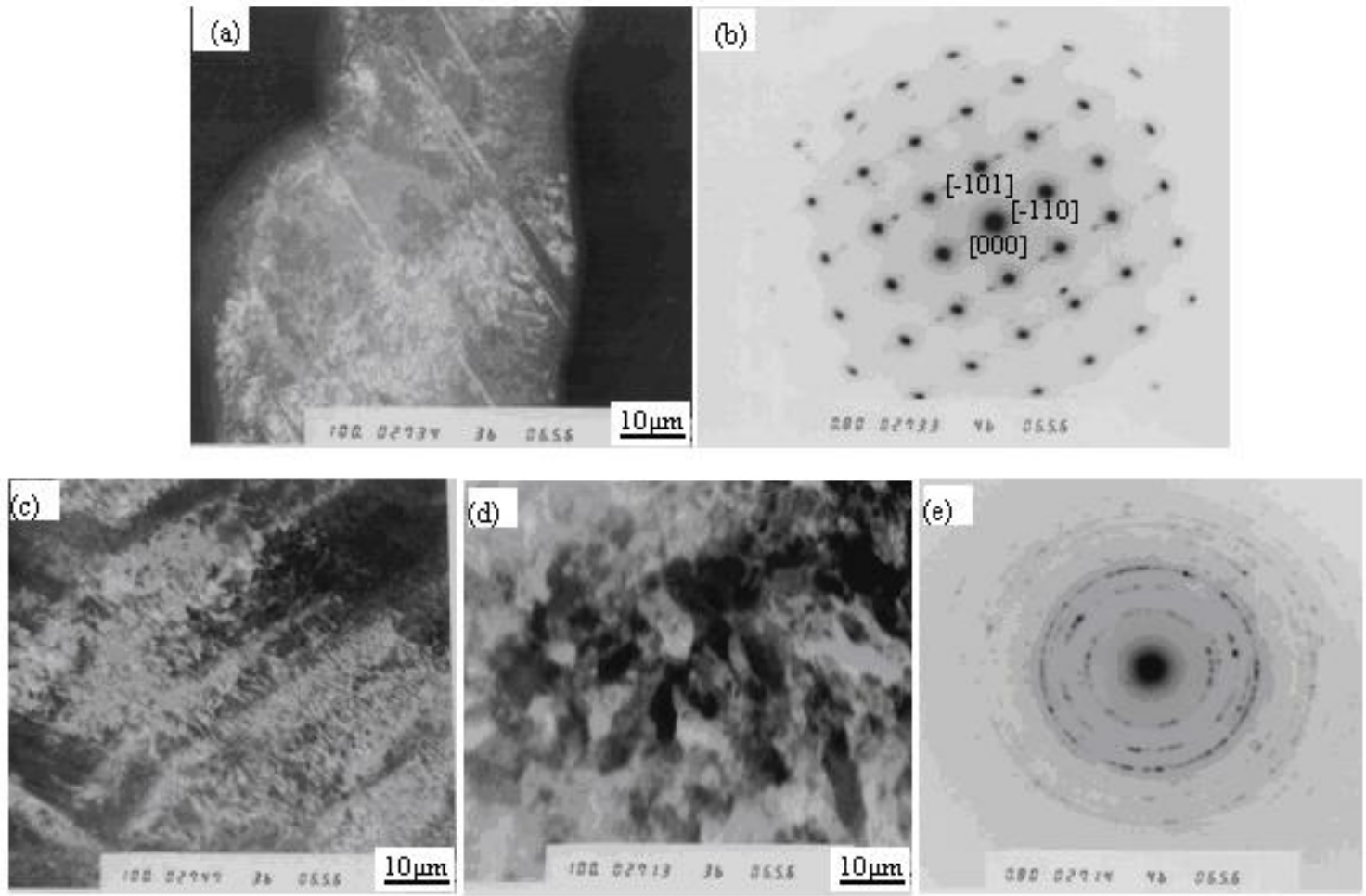

Fig. 3 TEM micrographs of cool-drawing austenitic stainless steel wires

(a) micrographs of twin-substructured martensite (b) diffraction patterns of twin-substructured martensite

(b) micrographs of dislocation-substructured martensite (d) austenite with discontiguous crystal interfaces

(e) diffraction patterns of austenite with discontiguous crystal interfaces

Applied stress (strain) helps the formation of martensite, the highest temperature $\mathrm{M}_{\mathrm{d}}$ point of producing martensite by cold working is generally higher than the temperature $\mathrm{M}_{\mathrm{s}}$ point of changing austenite into martensite spontaneously in the cooling. In the cold deformation stress, the stability of the austenite is reduced, partly transformed into a strain-induced martensite. The empirical formula for transition temperature of strain-induced martensite stretched $30 \%$ is as follows $[2,4]$ :

$\mathrm{Md} 30\left({ }^{\circ} \mathrm{C}\right)=413-9.5 \mathrm{Ni}-13.7 \mathrm{Cr}-8.1 \mathrm{Mn}-9.2 \mathrm{Si}-18.5 \mathrm{Mo}-462 \mathrm{C}+\mathrm{N}$

The content of each element is the weight percentage in (1) formula. After calculation, the highest temperature $\mathrm{Md}_{30}$ point of $0 \mathrm{Cr} 18 \mathrm{Ni} 9 \mathrm{Ti}$ stainless steel having a diameter of $\Phi 6 \mathrm{~mm}$ wire producing strain-induced martensite is $20^{\circ} \mathrm{C}$. Cold deformation of steel wire used in this experiment is more than $35 \%$, thus corresponding $\mathrm{M}_{\mathrm{d}}$ point is certainly higher than $20{ }^{\circ} \mathrm{C}$. Literature [4] showed that $\mathrm{Fe}-\mathrm{Ni}$ and $\mathrm{Fe}-\mathrm{Ni}-\mathrm{C}$ alloy in uniaxial tension make the $\mathrm{M}_{\mathrm{d}}$ point increase, while the three-hydraulic makes the $\mathrm{M}_{\mathrm{d}}$ point drop; the stress state of drawing is more conducive than rolling when changing to deformation martensite. It can be further concluded that the materials used in this experiment occurred the transformation of strain-induced martensitic definitely.

The martensite generated by Calibration deformation diffraction pattern is $\alpha$ 'phase (As shown in Figure3 (a) (b)). Literature[4] considered that there are three ways in the martensitic transformation: $\gamma \rightarrow \varepsilon, \gamma \rightarrow \alpha^{\prime}$ and $\gamma \rightarrow \varepsilon \rightarrow \alpha^{\prime}$. Literature[10] considered that $\varepsilon$ is the transition middle phase of $\gamma \rightarrow \alpha^{\prime}$, its content has remained around $5 \%$ in the process of transformation. In the $\varepsilon$-phase junction, $\alpha$ 'easy nucleated, and because $\gamma \rightarrow \alpha^{\prime}$ has a large shear, thus prompting $\varepsilon$-phase formatted. Therefore, we believe austenite martensite transformation approach is varied, with specific conditions. In this study, 18-8 stainless steel cold drawing observations induced martensitic transformation in no $\varepsilon$ phase, but can't completely exclude the possibility of $\varepsilon$ phase is too small and difficult to observe.

Through the TEM experiments, we observe the detailed sub-structure of martensite, and find not 
only twin-substructured martensite, but also dislocation-substructured martensite. In general, high density twin-substructured martensite often shows in the low carbon martensitic. In the high-carbon or high content alloy, the sub-structure usually fine twin-substructured martensite. Accordingly, the phase of the material $0 \mathrm{Cr} 18 \mathrm{Ni} 9 \mathrm{Ti}$ used in this experiment changed into a large amount of fine flake twin-substructured martensite, but in the drawing process, the parent phase austenite generates a high density of twin-substructured martensite due to large deformation. These dislocations are retained in a subsequent change in the martensite, thus drawing the austenitic steel substructure of martensite generated in both twin-substructured martensite and dislocation-substructured martensite.
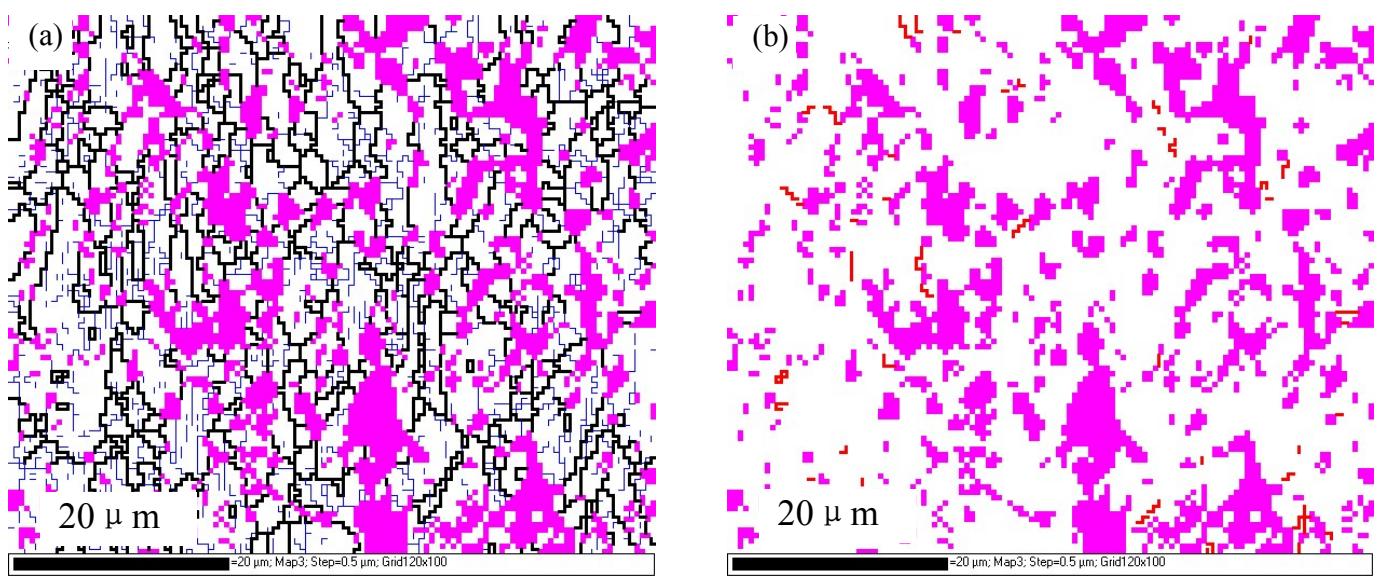

Fig. 4 EBSD micrographs of cool-drawing austenitic stainless steel wires

\subsection{EBSD micrographs of cool-drawing austenitic stainless steel wires}

Martensitic transformation occurs due to the lattice constant of sudden significant changes, and with the different alloy content and the amount of deformation, the c/a value is different. The EBSD experiments requiring precise sure c/a value in order to calibrate martensite. Thus in the study, calibrated martensite directly in EBSD is difficult.From the foregoing TEM results, we used the "exclusion" to be determined. In EBSD experiments, we calibrated phase has a face-centered cubic structure is austenite, the rest are Martensite-centered cubic.

In Figure 4, the black is martensite, the white is austenite. Figure 4 (a) of the thick black wire is the high angle grain boundaries, black thin small angle grain boundaries, Fig. 4 (b) austenitic black line inside the twin boundaries.

As seen in Figure 4, austenite grain size of micrometer scale. Optical microscopy and electron microscopy analysis of the foregoing, do not see the austenite grain boundaries, This is due to the strong large deformation so that the grain boundaries are broken, The austenite discontinuous grain boundaries so that it exhibits annular pattern (Figure 3 (e)) at the time of diffraction. As we all know, Deformation can refine the grain to a certain extent, however, the EBSD experiments we see austenite grain is far from refined to nan scale crystallites (Figure 3 (d)) degree. Therefore, Figure 3 (e) as shown in TEM experiments annular diffraction pattern should be broken due to the austenite grain boundaries results, not due to the nan scale diffraction crystallites.

\subsection{Discussion on the chemical composition of Austenitic stainless steel wire of metal rubber}

As mentioned above, in the SEM experimental observations, we saw that due to alloying elements titanium, which strongly promote brittle phase formation, exist in the 0Cr18Ni9Ti stainless steel, as well as its relatively high chromium and nickel content, cold deformation induced the formation of brittle phases, thereby generating a spindle of micro holes in steel wire. If the alloying elements titanium was removed and the content of chromium and nickel was reduced appropriately, the formation of brittle $\sigma$ phase must be able to be suppressed to some extent.

In addition, [11] determines that the amount of strain-induced martensite to which $\mathrm{Cr} 17-\mathrm{Ni} 7$ austenitic stainless steel wire in the cold deformation of $35 \%$ corresponds is $80 \%$, by X-ray diffraction method. After the quantitative metallographic analysis of the results of earlier EBSD experiment (Figure 4), 0Cr18Ni9Ti stainless steel wire in the cold deformation of 35\% corresponds to the amount of strain-induced martensitic transformation was $38 \%$. This is due to the $\mathrm{Cr} 17-\mathrm{Ni} 7$ 
austenitic is more unstable than $\mathrm{Cr} 18-\mathrm{Ni} 8$ system, the transformation of strain-induced martensitic would occur easier when the deformation take place. And more strain-induced martensite will help to improve the strength of steel. In view of this, we initially believe that $\mathrm{Cr} 17-\mathrm{Ni} 7$ austenitic stainless steel wire may be more suitable for the preparation of metal rubber material in high damping.

\section{Conclusions}

(1)Under this experimental condition, martensitic transformation was induced due to the deformation caused by the cold drawing of stainless steel wire. The resulting martensite was $\alpha$ 'phase, the sub-structure is dislocations and twins;

(2)Under this experimental condition, the austenite grain boundaries are broken due to the large deformation caused by the cold drawing of stainless steel wire.

(3)Under this experimental condition, the formation of brittle phase $\sigma$ phase was induced due to the large deformation caused by the cold drawing of stainless steel wire.

(4)The Cr17-Ni7 austenitic stainless steel wire of low alloy content and metastable state is supposed to be more suitable for the preparation of metal rubber material.

\section{References}

[1] Chegodayev, MU Liukin, Kerr Turpin. Design of Metal Rubber Element. Zhongying Li translation. Beijing:National Defense Industry Press, 2000: 7, 14, 28〜30， 32.

[2] Shiying Lu, Tingkai Zhang, Xifan Kang. Stainless Steel (Specialty Steel Series). Beijing:Atomic Energy Press. 1995: $161 \sim 198,216 \sim 229$.

[3] Jimei Xiao. Stainless steel metal issues (Second Edition). Beijing:Metallurgical Industry Press, 2006: $21 \sim 122, \quad 213 \sim 225$.

[4] Yaozu Xu.Martensite and Martensite(second edition). Beijing:Science Press,1999: 64, 691 796.

[5] Luoping Xu, Meitang Shi, Guangjie Shao. The Influences of Heat Treatment and Cold Deformation on microstructure and properties of 18-8 austenitic stainless steel. Shanghai Metal, 1993, 15(5): $18 \sim 22$.

[6] Liping Mao, Guoyue Su, Fanya Kong. Study of Microstructure of Super-high Strength 1Cr18Ni9Ti Stainless Steel Silk. Heat Process. 2004(2): 32 33.

[7] Chunchun $\mathrm{Xu}$, Xinsheng Zhang. Gang Hu. Deformation Induced Martensite of Cold Worked Stainless Steel and Its Corrosion Behaviors. Materials Protection. 2002，35(3): 15 17 .

[8] Shuhua Wang, Dezhuang yang, Shiyu He. Fatigue behavior of 1Cr18Ni9Ti steel at low temperatures and in vacuum. Materials Science and Technology. 2004, 12(6): 625 629.

[9] Gang Li, Ruihua Zhu. Analysis of Deformation Induced Martensitic Transformation. Rare metal materials and Engineering. 1991, 20(5): 18 22.

[10]Hongning Kou, Guoquan Liu, Jianchun Yang. Microstructure and Mechanical Properties of Cr-Ni-Mn Stainless Steel Wire Used for Metal Rubber. Journal of Aeronautical Materials. 2006(8), 26 (4) : 32 33. 